ISSN 1112-9867

\title{
EFFECT OF COPPER ON PASSIVITY AND CORROSION BEHAVIOR OF FE-XC- 5CU ALLOY
}

\author{
M. Ferhat* ${ }^{1,2}$, A. Benchettara ${ }^{2}$, S E Amara ${ }^{2}$ \\ ${ }^{1}$ University Amar Télidji of Laghouat, BP37G Route de Ghardaia-Laghouat, Algeria \\ ${ }^{2}$ Laboratoire d'Electrochimie-Corrosion, Métallurgie et Chimie Minérale, Faculté de Chimie, \\ USTHB, BP 32 El-Alia, Bab Ezzouar, Alger 16111, Algeria
}

Received: 22 January 2014 / Accepted: 14 March 2014 / Published online: 30 June 2014

\begin{abstract}
:
The correlation between corrosion behavior rate of annealed $\mathrm{Fe}-\mathrm{xC}-5 \mathrm{Cu}$ alloys and their microstructure and phase composition is presented. The metallurgical analyses, including, $\mathrm{X}$ Ray diffraction (XRD), the scanning electron microscopy (SEM) with energy dispersive analysis (EDX), and induction hardening characterization are conducted to study the $\mathrm{Fe}-\mathrm{C}-\mathrm{Cu}$ alloys. Corrosion parameters in $\mathrm{H}_{2} \mathrm{SO}_{4} 1 \mathrm{~N}$ solution have been established by carrying out electrochemical studies such as potentiodynamic (Tafel polarization and linear polarization, LP) and electrochemical impedance spectroscopy (EIS). The coupled effect copper/microstructure is discussed. Alloying $\mathrm{Cu}$ showed a beneficial effect on hypoeutectoid steel and harmful effect on hypereutectoid steel. The improved corrosion resistance is related to cementite morphology and by a copper dissolution/re-deposition process.
\end{abstract}

Keywords: Corrosion; Copper; cementite; EIS; Passivation; Hardness.

\section{INTRODUCTION}

The $\mathrm{Fe}-\mathrm{C}-\mathrm{Cu}$ system is of interest for ferrous and nonferrous metallurgy. It is known that copper provides hardening in steel and cast iron, noticeably raises the corrosion resistance, improves the deformability of steels, and influences the antifriction properties and the wear resistance of graphitized steels.

Author Correspondence, e-mail: m.ferhat@mail.lagh-univ.dz

ICID: 1111606 
The copper rich alloys of the system are promising as new cost effective, high strength, high conductivity copper alloys. However, in some cases, the presence of copper in ferrous alloys has negative aspects. Seo et al. [1] established that copper reduces the stability of the passive layer. It is known that a small amount of residual copper in steel scrap, which is difficult to remove by conventional steelmaking process, is a reason of "surface fissures" during hot rolling process. The solubility of copper in solid iron, and therefore the influence of carbon on the solubility, is considered as important factors affecting surface fissures formation. Features of phase relations in the $\mathrm{Fe}-\mathrm{C}-\mathrm{Cu}$ alloys appeared to help solving the problem of copper separation from steel scrap, which is important for both metallurgical processing difficulties and environmental problems.

Depending on the copper content, the chemical composition of the iron in relation to other elements can influence the kinetics of formation of the structure [2]. Copper can change the intensity of pearlite formation and produce an ambiguous effect on the mechanical properties of irons [3]. The causes and mechanisms of this complex action of copper have not been studied exhaustively, though in the recent years the studies and applications of copper and copper steel irons have been amplified [4-7].

It was reported in previous studies that the mechanism of the beneficial effect of copper addition on the stainless steels is based on the suppression of anodic dissolution by the noble metallic copper enriched on the surface film of austenitic stainless steels in sulfuric acid [8, 9]. The deposition of copper on a locally corroded surface was recognized for both ferritic and austenitic stainless steels $[10,11]$. A recent study showed that copper improves the pitting corrosion resistance through re-deposition of previously dissolved copper [12-14]. Although the effect of copper metals on active-passive transition is widely studied, the influence of copper on the stability of a passive film is not sufficiently recognized. Though copper does not have high solubility in steels, the solubility of copper in ferrite is $\sim 0.2 \%$ [15] and $\sim 4 \%$ in austenite [16], its addition is interesting from the prospect of precipitation strengthening and improvement of corrosion resistance. The precipitation strengthening of ferritic and ferriticaustenitic steels by $\mathrm{Cu}$ rich bcc precipitates is well known since the early work of Russell et al [17]. At high copper concentration, special phase $(\varepsilon-\mathrm{Cu})$ not dissolving in the main phases is formed. $\varepsilon-\mathrm{Cu}$ was designated as a copper-rich phase containing $4 \mathrm{wt} \% \mathrm{Fe}$ (at $1094^{\circ} \mathrm{C}$ ), or less, according to the temperature [18]. The progressive transition of coherent bcc $\mathrm{Cu}$ precipitates to incoherent fcc $\varepsilon-\mathrm{Cu}$ with increasing size is well characterized by Heo et al [19]. The small grains of this phase contain up to $96 \% \mathrm{Cu}$. The presence of the $\varepsilon-\mathrm{Cu}$ in ferrite increases the hardness of ferritic steels [20]. Dispersed inclusions of this phase can influence the stability of 
passive film and therefore susceptibility of ferrite to pitting corrosion [21]. In literature only few studies of the $\mathrm{Fe}-\mathrm{C}-\mathrm{Cu}$ alloys with the copper, concentration higher than $5 \mathrm{wt} \%$, is at hand [22-24].

Our study presents the influence of high content copper on the stability of passive film on the surface of two different microstructure alloys when the precipitation of the $\varepsilon-\mathrm{Cu}$ is possible and when indirect influence of copper on morphology cementite precipitation is observed.

\section{MATERIALS AND METHODS}

\subsection{SAMPLES PREPARATION}

The alloy samples are produced by arc melting on water-cooled copper crucible by electromagnetic high frequency (HF) under argon atmosphere (Table 1). The samples are prepared with a total weight of $30 \mathrm{~g}$ by weighing appropriate of the components with purity of $\mathrm{Fe}$ (Aldrich 99.89\%), $\mathrm{Cu}$ (99.98\%) and graphite. The alloys buttons are melted two times for better homogenization. The weight loss was less than $2 \%$ after melting (Fig-1). The melted alloy buttons are sealed in evacuated quartz tubes for homogenization heat treatment. The alloy was homogenized at $500^{\circ} \mathrm{C}$ for $60 \mathrm{~min}$, and at $1000^{\circ} \mathrm{C}$ for $60 \mathrm{~min}$. After the heattreatment, the alloys are machined using an electrodischarge machine (EDM), samples are cut as $10 \mathrm{~mm}$ diameter disks. For metallographic characterization and electrochemical measurement the specimens are respectively hot and cool mounted in resin, four samples are prepared for each alloy to guarantee the reliability of the results.

Table 1. Composition of the alloys

\begin{tabular}{|c|c|c|c|c|c|c|c|}
\hline \multirow{2}{*}{ 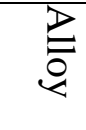 } & \multicolumn{2}{|l|}{$\mathrm{Fe}$} & \multicolumn{2}{|l|}{$\mathrm{Cu}$} & \multicolumn{2}{|l|}{$\mathrm{C}$} & \multirow{2}{*}{$\mathrm{VHN}_{0}$} \\
\hline & $\mathrm{wt} \%$ & at\% & $\mathrm{wt} \%$ & at $\%$ & wt $\%$ & at $\%$ & \\
\hline (A) & 94,8 & 94,68 & 5 & 4,39 & 0,2 & 0,93 & 161 \\
\hline (B) & 93,5 & 89,00 & 5 & 4,39 & 1,5 & 6,61 & 323 \\
\hline
\end{tabular}

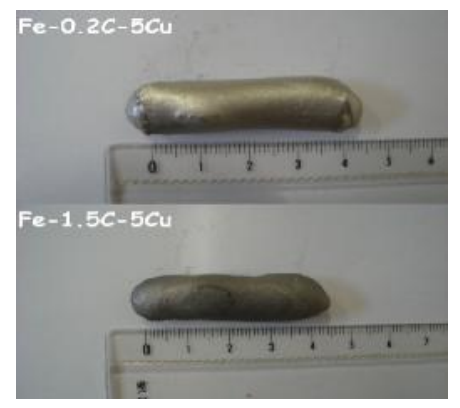

Fig.1. The annealed alloys before cutting 


\subsection{SAMPLES ANALYSIS}

X-ray diffraction analysis was used to identify the present phases in the samples (Fig-2). Microstructures of the samples are studied using metallographic samples prepared by sequential polishing with silicon carbide emery paper followed by diamond polishing. Polished samples are etched using $4 \%$ Nital for 30s. The scanning electron microscopy (SEM) with energy dispersive analysis (EDX) was used for microstructural analysis. The Metallographic of the elaborated alloys was performed on a FEI Quanta 400 Scanning

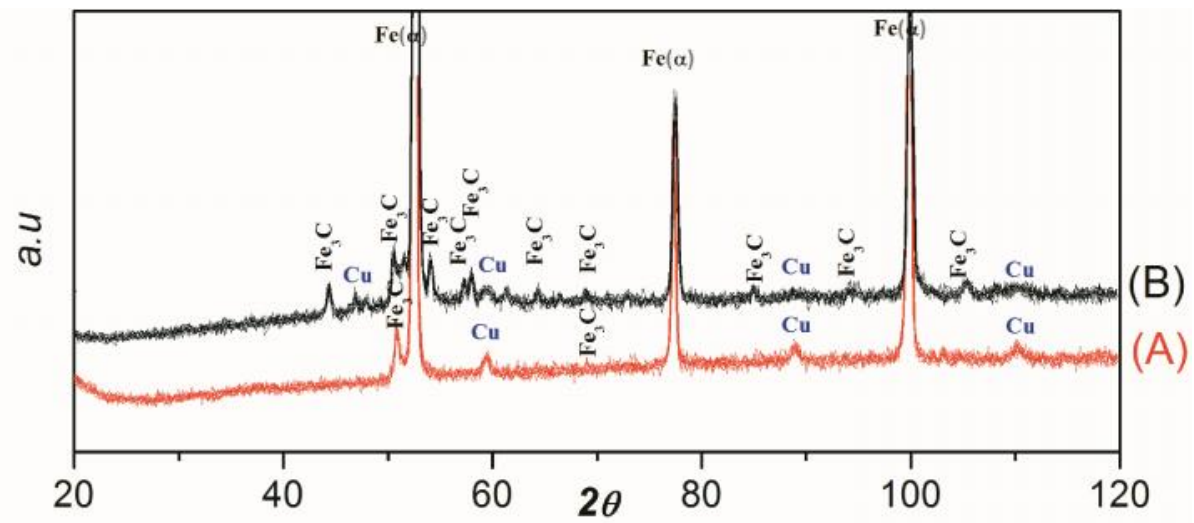

Figure 2: $\mathrm{X}$-ray diffraction patterns of $\mathrm{Fe}-\mathrm{xC}-5 \mathrm{Cu}$ alloys

Electron Microscope (SEM) using backscattered electrons to verify the chemical composition of copper. The average copper fraction was automatically measured. The micro-Vickers hardness testing was carried out on the $\mathrm{Fe}(\mathrm{C}, \mathrm{Cu})$ alloys. The average value of six readings was recorded for each hardness point. Metallography of the elaborated alloys was performed with an optical microscope.

\subsection{Electrochemical measurements}

The corrosion behavior of the samples was evaluated by using an EG \& G Potentiostat/Galvanostat Model 273A corrosion measurement system, driven by 352 SoftCorr III software, for linear polarization (LP) measurements, a sweep from -30 to $+30 \mathrm{mV}$ versus open-circuit potential at a sweep rate of $0.1 \mathrm{mV} . \mathrm{s}^{-1}$ was used and the polarization resistance $\left(R_{p}\right)$ was measured from the slope of $E$ vs $i$ curve in the vicinity of corrosion potential. Electrochemical impedance spectroscopy (EIS) was measured using PGZ 301 Potentiostat/Galvanostat and a Solartron 1255 frequency response analyzer withVolta master 4 software. EIS was recorded at open circuit potentials $E_{o c p}$, in the frequency ranging from $100 \mathrm{kHz}$ to $10 \mathrm{mHz}$, with a sinusoidal signal perturbation of $10 \mathrm{mV}$. The software ZView 2.3 (Scribner Associates) was used for analyzing the EIS results. The impedance plot forms a 
semicircle, the diameter of which gives the charge-transfer resistance. This can be used in a Stern-Geary type equation to determine the corrosion current density, $I_{\text {cor }}$, and thus the corrosion rate: $I_{\text {cor }}=1 / 2.3 \times \beta_{a} \beta_{c} /\left(\beta_{a}+\beta_{c}\right) \times 1 / R_{c t}$

The alloy was mechanically ground with emery paper up to 1200 grit, degreased in acetone, rinsed with bidistilled water, dried and transferred quickly in a Tacussel glass cell filled with $100 \mathrm{~mL}$ of naturally aerated $\mathrm{H}_{2} \mathrm{SO}_{4} 1 \mathrm{~N}$ solution. A saturated sulfate electrode (SSE) and graphite electrode are used as reference and auxiliary electrodes, respectively. All measured potentials are reported to this reference electrode.

\section{RESULTS AND DISCUSSION}

\subsection{Microstructure}

The choice of these alloys makes the quantity of cementite increase and the structure change from the ferritic to the ferrite-cementite one corresponding to the carbon content. The XRD curve of $\mathrm{Fe}-0.2 \mathrm{C}-5 \mathrm{Cu}(\mathrm{A})$ and $\mathrm{Fe}-1.5 \mathrm{C}-5 \mathrm{Cu}$ (B) (Fig-2) mainly constituted of the major peaks of the ferrite iron phase $(\alpha)$ and the cementite phase. Besides these dominant peaks, small peaks related to copper phase are detected in the XRD spectrum of the two alloys. The greatest difference between the XRD curves of the alloys (A) and (B) is the greater intensity of peaks associated with the cementite phase in the XRD curve of alloy (B) as compared to alloy (A). However the copper phase was present in the greatest amounts in alloy (B). Hypoeutectoid steel, Alloy (A), is ferrite and pearlite, diffusion of carbon produced an allpearlite structure and more copper dissolved in the iron, this reduced the amount of free copper, hence lowering the overall hardness of the constituent (Fig-3(a)).

Copper promotes stabilization and refinement of pearlite as mentioned by Amara et al [2]. Sil'man et al [15] also explained that the copper increases the stability of austenite.

In hypereutectoid steel (alloy (B)) the XRD analyses and microstructure (Fig-2 and Fig-3) 
indicates both of pro-eutectoid cementite and $\varepsilon-\mathrm{Cu}$ exist. The size and shape of the $\varepsilon-\mathrm{Cu}$ particles within cementite varies significantly. EDS-X-ray microanalysis performed on this two microstructures showed that copper concentration possessed a non-uniform chemical composition. It is interesting to note that the concentration of $\mathrm{Cu}$ is deviated from the original composition, since the calculated average concentration of copper is less than the real concentration (see tables on Fig-3(C) and (D)). The amount of $\varepsilon-\mathrm{Cu}$ phase in this alloy cannot be calculated on the basis of the presented data because we do not know the solubility of copper in the other phases of the eutectoid mixtures and the composition of copper itself has been determined only approximately. As mentioned by Banas et al [21]; the stability of proeutectoid cementite is a result of thermokinetic processes that accompany the phase transformations in iron and steel alloyed with copper. The mechanism of formation of $\varepsilon-\mathrm{Cu}$ is due to the cementite plates formed in the eutectoid transformation. It squeezes the copper earlier dissolved in these austenite volumes due to the very low solubility of copper. The latter strengthen the pro-eutectoid cementite and slightly increase the bulk hardness of this constituent (Fig-4(a)).The ferrite layers formed in the process also emit a part of the dissolved copper and it accumulates on the boundaries between the cementite flakes and the ferrite layers enveloping the cementite plates as shown in Fig-3(B) and related in [16]. Fig-4(b), show the variation of Vickers hardness VHN as function of the reverse of the indentation $d$
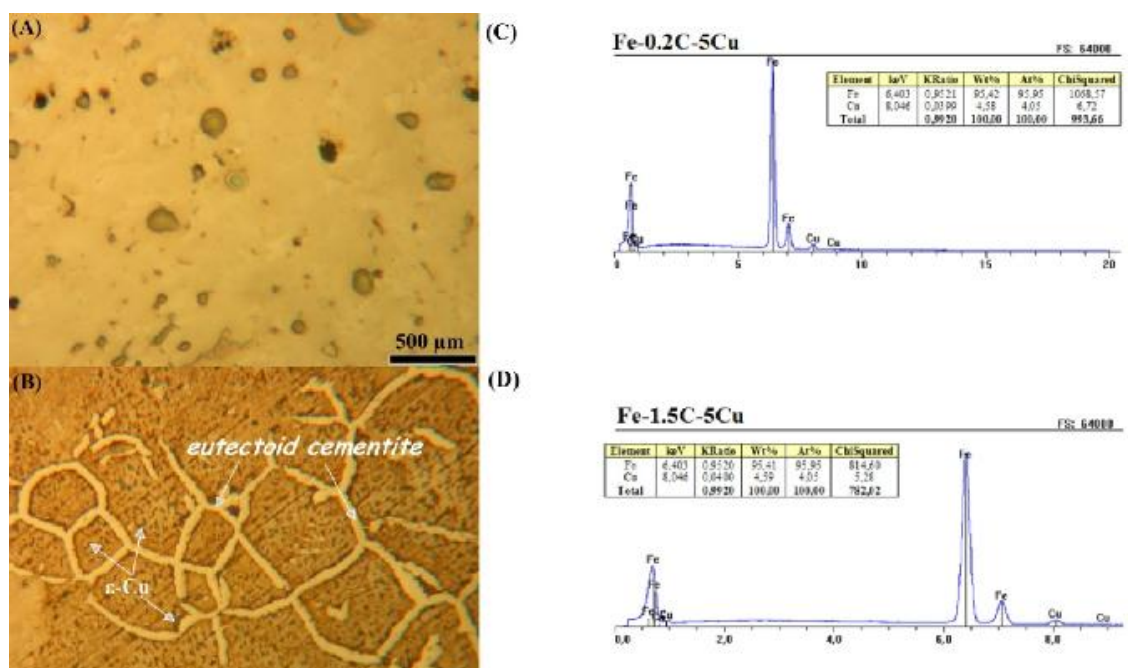

Fig.3. Optical micrograph of $\mathrm{Fe}-\mathrm{xC}-5 \mathrm{Cu}$ alloys, etched with $4 \% \mathrm{Nital}$ (A),(B). SEM backscattered electron microanalyses performed of copper concentration on for each alloy; $\mathrm{VHN}_{0}$ are calculated from the origin of the lines $\mathrm{VHN}$ vs $1 / \mathrm{d}$, $\left(V H N_{d \rightarrow \infty}=V H N_{0}\right)$, consequently, the $\mathrm{VHN}_{0}$ increases from 161 of the alloy (A) to $323 \mathrm{HVN}$ 
for alloy (B). The small particles of the dispersed $\varepsilon-\mathrm{Cu}$ in the hypereutectoid microstructure have influenced the hardness values and increase the bulk hardness of the alloy (B). The introduction of copper into hypereutectoid steel coarsens the microstructure of the particles and increases the grain size, whereas the introduction of copper into hypoeutectoid steel refines the microstructure elements.

\subsection{Electrochemical studies}

Cyclic polarization curves for the Fe-C-Cu alloys in $\mathrm{H}_{2} \mathrm{SO}_{4} 1 \mathrm{~N}$ studied are shown in Fig-5. Cyclic Polarization measurements are performed in order to determine the tendency of the alloys to undergo localized (pitting or crevice) corrosion when placed in the electrolyte solutions. The arrows indicate potential scan directions. The samples are kept at the free corrosion potential for $30 \mathrm{mn}$ and then the cyclic polarization responses are measured from 250 with respect to the corrosion potential to $1600 \mathrm{mV} / \mathrm{SSE}$ and back of each sample in $\mathrm{H}_{2} \mathrm{SO}_{4}$ $1 \mathrm{~N}$ conducted at a sweep rate of $0.5 \mathrm{mV} / \mathrm{s}$. Curves show a typical current-potential $(i-E)$ polarization, several characteristic regions can be distinguished results are showed on table 2 . It is found that the general appearance of potentiodynamic curves significantly changes as the microstructural morphology changes. The appearance of the anodic curve (active region) seems unchanged for both alloys; the dissolution reaction of iron is not affected by the

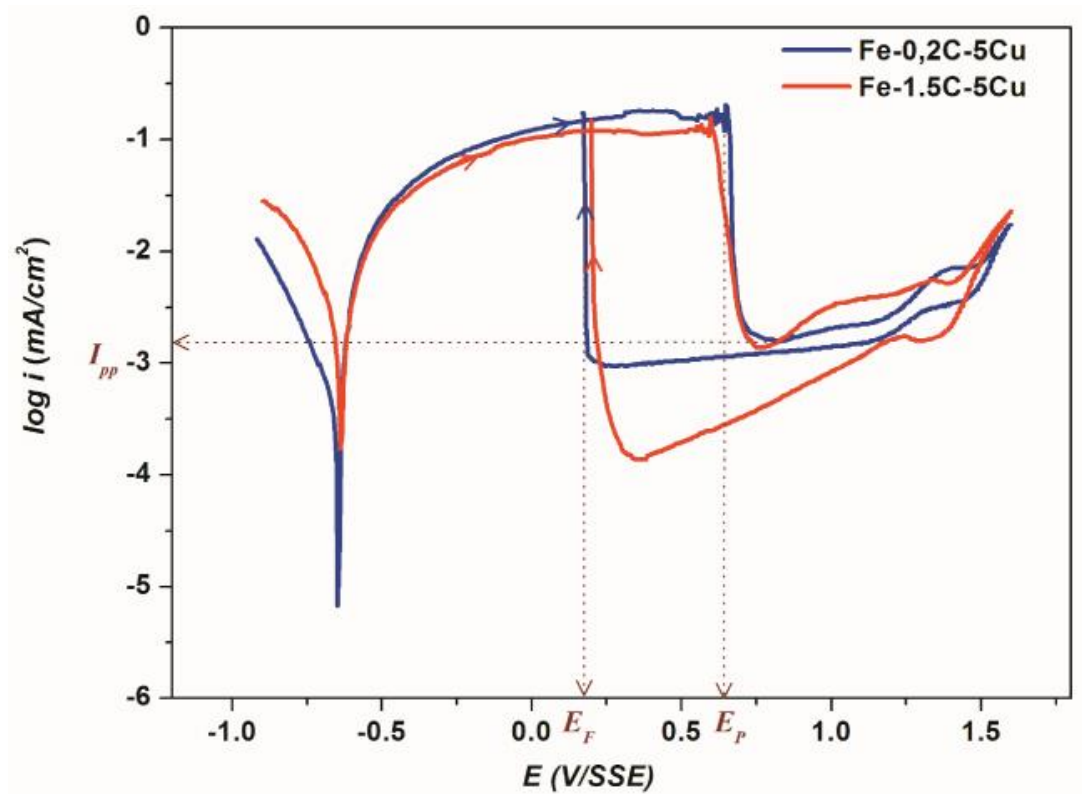

Figure 5: Cyclic Polarization Curves of the alloys in $\mathrm{H} 2 \mathrm{SO} 41 \mathrm{~N}$ medium. Sweep rate $0.5 \mathrm{mV} / \mathrm{s}$.

cementite morphology. However, the anodic polarization behavior of the annealed samples was different in the secondary passive potential region. For example at $1000 \mathrm{mV} / \mathrm{SSE}$ the anodic current of $\mathrm{Fe}-1.5 \mathrm{C}-5 \mathrm{Cu}$ alloy is greater than on $\mathrm{Fe}-0.2 \mathrm{C}-5 \mathrm{Cu}$ alloy; the high amount of 
free copper is oxidized by the dissolved oxygen, since the potential of $\mathrm{O}_{2} / \mathrm{H}_{2} \mathrm{O}\left(E^{0}=\right.$ $+1.23 \mathrm{~V} / E N H)$ system is greater than $\mathrm{Cu}^{2+} / \mathrm{Cu}\left(E^{0}=+0.34 \mathrm{~V} / E N H\right)$ system. Cyclic polarization curves also reveal a more resistant oxide film on sample (A) than on (B) at anodic potentials. The electrochemical parameters obtained from LPR and EIS are given in Table 3. Cathodic curves are more influenced, the $\beta \mathrm{c}$, which is connected with the kinetics of the Hydrogen evolution reaction (HER), shows similar catalytic activity of these two alloys with different microstructures and different compositions. Cathodic current start increasing from $E_{\text {ocp }}$ with increasing potential due to the reduction of hydrogen, which is more pronounced in the presence of pro-eutectoid cementite (alloy $\mathrm{Fe}-1.5 \mathrm{C}-5 \mathrm{Cu}$ ). Copper has a low diffusivity and solubility in $\mathrm{Fe}_{3} \mathrm{C},\left(D_{\mathrm{Cu} \text { in } \mathrm{Fe}_{3} \mathrm{C}}^{832}=2.6 * 10^{-21} \mathrm{~m}^{2} \cdot \mathrm{s}^{-1}\right.$ [25]) since the corrosive medium becomes more oxidant with the presence of $\mathrm{Cu}^{2+}$ cations. This behavior is confirmed by the shift of the apparent transpassive region to lower potentials (about $962 \mathrm{mV} / \mathrm{SSE}$ ) leading the local attacks to occur. However, instead of oxygen being evolved, the metal corrodes locally with formation of visible pits. Also the higher obtained corrosion current density $\left(8.29 \mu \mathrm{A} / \mathrm{cm}^{2}\right)$ indicates a greater number of active corrosion sites that can be responsible for localized corrosion. In $\mathrm{Fe}-0.2 \mathrm{C}-5 \mathrm{Cu}$ curve, the transpassive region shifts towards more positive potentials, thus, leading to the conclusion that, the passivation film is more stable. A negative hysteresis is obtained in cyclic polarization curves. Hysteresis can provide information on pitting corrosion rates and how readily a passive film repairs itself.

Table 2. Different potentials calculated from cyclic curves $\mathrm{I}-\mathrm{E}$ of the $\mathrm{Fe}(\mathrm{C}, \mathrm{Cu})$ alloys

\begin{tabular}{l|lllll}
\hline \hline Alloy & $\begin{array}{l}E_{\text {cor }} \\
(\mathrm{mV} / \mathrm{SSE})\end{array}$ & $\begin{array}{l}E_{F} \\
(\mathrm{mV} / \mathrm{SSE})\end{array}$ & $\begin{array}{l}E_{p} \\
(\mathrm{mV} / \mathrm{SSE})\end{array}$ & $\begin{array}{c}\Delta \\
(\mathrm{mV} / \mathrm{SSE})\end{array}$ & $\begin{array}{l}i_{p p} \\
\left(\mu \mathrm{A} / \mathrm{cm}^{2}\right)\end{array}$ \\
\hline (A) & -676 & 167 & 658 & 1334 & 2 \\
$(\mathrm{~B})$ & -636 & 202 & 602 & 1238 & 1.74 \\
\hline \hline
\end{tabular}

Alloy Fe-0.2C-5Cu exhibit a small hysteresis loops in sulfuric acid electrolyte indicating high resistance to localized corrosion, which is not the case for the alloy $\mathrm{Fe}-1.5 \mathrm{C}-5 \mathrm{Cu}$, a large hysteresis loop is observed; then a more susceptibility to pitting corrosion. Negative hysteresis occurs when a damaged passive film repairs itself and pits do not initiate. Two important potentials, are used to characterize the hysteresis loop; Flade potential $\left(E_{F}\right)$ when electrode activation takes place during the reverse potential scan and primary passivation potential $\left(\mathrm{E}_{\mathrm{P}}\right)$, which is higher than $\mathrm{E}_{\mathrm{F}}$, and occurred during the forward scan. It was reported in [26] that in $\mathrm{Fe} \mid \mathrm{nM} \mathrm{H}_{2} \mathrm{SO}_{4}$ system, Flade potential is connected with local $\mathrm{pH}$ and varies 
inversely with the $\mathrm{pH}$. In the case of the $\mathrm{Fe}-0.2 \mathrm{C}-5 \mathrm{Cu} \mid 0.5 \mathrm{M} \mathrm{H} \mathrm{H}_{2} \mathrm{SO}_{4}$ system for which $\mathrm{E}_{\mathrm{F}}=$ $167 \mathrm{mV}$, the local $\mathrm{pH}$ is higher than $\mathrm{Fe}-1.5 \mathrm{C}-5 \mathrm{Cu} \mid 0.5 \mathrm{M} \mathrm{H}_{2} \mathrm{SO}_{4}$ system. The increase in local $\mathrm{pH}$ indicates conditions more favorable to passive film formation; thereby reducing the overall free energy of the system, and hence, greater stability of passivity. The more positive the value of $E_{P}$, the more resistant the alloy is to initiation of localized corrosion. The difference between $\mathrm{E}_{\text {cor }}$ and $\mathrm{E}_{\mathrm{p}}$ in $\mathrm{Fe}-0.2 \mathrm{C}-5 \mathrm{Cu}(\Delta E=1334 \mathrm{mV})$ is higher than in $\mathrm{Fe}-1.5 \mathrm{C}$ $5 \mathrm{Cu}(\Delta E=1238 \mathrm{mV})$. A decrease in this difference has been associated with increased susceptibility to localized corrosion [27].

Impedance measurements are undertaken to provide information about the kinetics of electrochemical process on $\mathrm{Fe}-\mathrm{xC}-5 \mathrm{Cu} \mid 0.5 \mathrm{M} \mathrm{H}_{2} \mathrm{SO}_{4}$ interface. It is clear from the spectrum impedance of Fig-6(a) having semi-circle shape. This indicates that the corrosion process is mainly controlled by charge transfer [28]. The results obtained from dc measurement, Tafel curve and linear polarization resistance, and ac measurements, are in good agreement.

However a difference between $R_{L P R}$ and $R_{c t}$ on Fe-1.5C-5Cu alloy is noted, probably due to a little diffusion of $\mathrm{H}^{+}$ions, the latter is transported from the bulk solution to the steel surface by mass transfer, the local $\mathrm{pH}$ is increased. The impedance parameters obtained following the fitting of the EIS experimental results by using the EC displayed in Fig-6(c) are listed in Table 3. Two time constants are identified on Fig-6(a), a capacitive half circle in the high
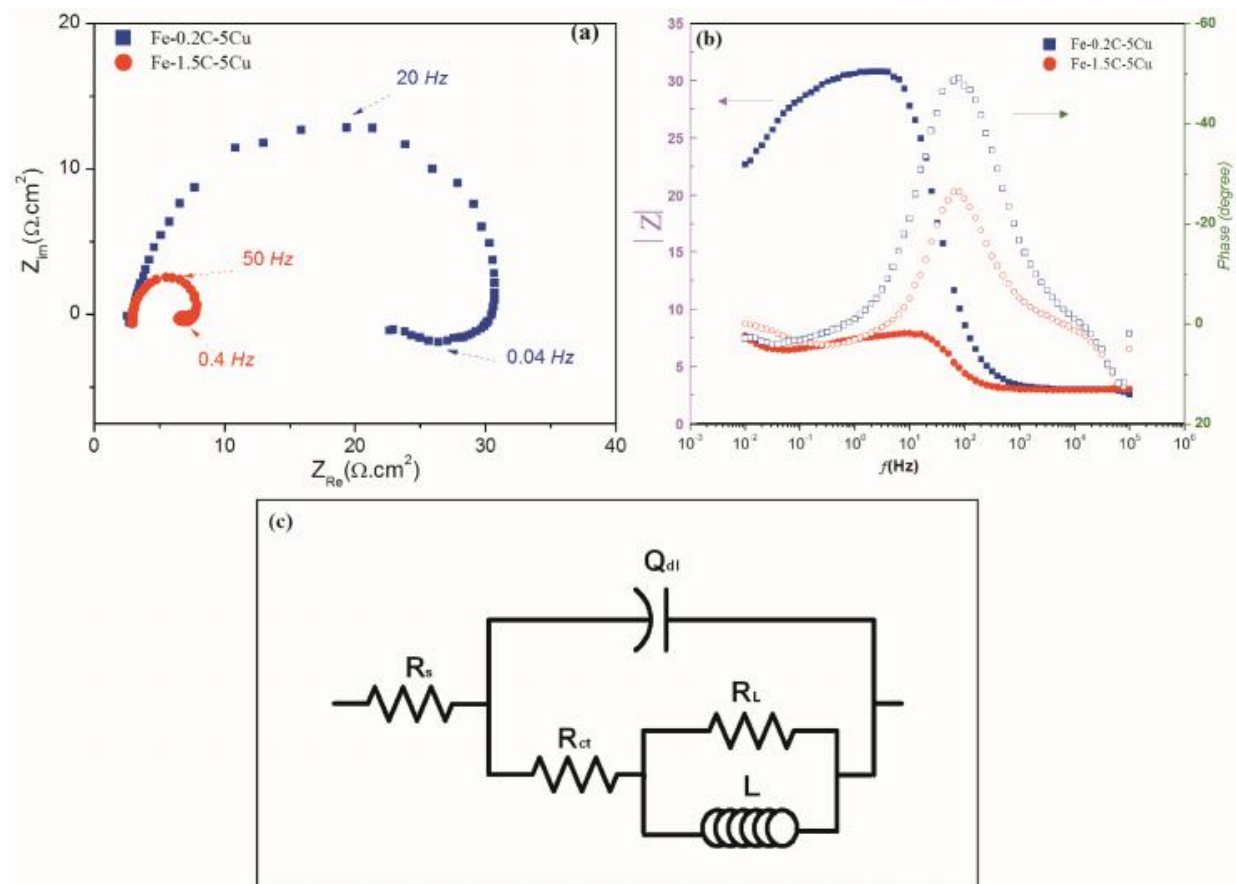

Figure6: Nyquist and Bode diagrams of the $\mathrm{Fe}-\mathrm{xC}-5 \mathrm{Cu}$ alloys at OCP vs. SSE in $\mathrm{H} 2 \mathrm{SO} 4 \mathrm{IN}(\mathrm{a}, \mathrm{b})$. Equivalent circuit used to simulate the EIS diagrams obtained from $\mathrm{Fe}-\mathrm{xC}-5 \mathrm{Cu}$ alloys in $\mathrm{H} 2 \mathrm{SO} 4 \mathrm{iN}$ (c).

(HF)-medium (MF) frequencies range, and an inductive loop in the low frequency (LF) 
range. The inductive half circle at low frequencies is related to the adsorbed intermediate product formed during the dissolution of electrode [29, 30].This inductive loop can be

Table 3. Electrochemical parameters deduced by Tafel, LPR and EIS method for Fe-xC-5Cu in $\mathrm{H}_{2} \mathrm{SO}_{4} 0.5 \mathrm{M}$

\begin{tabular}{|c|c|c|c|c|c|c|c|c|c|c|c|}
\hline \multirow{2}{*}{$\frac{\gtrless}{2}$} & \multirow{2}{*}{$\begin{array}{l}E_{\text {cor }} \\
\mathrm{mV} / \mathrm{SSE}\end{array}$} & \multicolumn{2}{|c|}{ Tafel } & \multicolumn{2}{|c|}{$L P R$} & \multicolumn{6}{|c|}{$E I S$} \\
\hline & & $\begin{array}{l}\beta a \\
\mathrm{mV} / \mathrm{dec}\end{array}$ & $\begin{array}{l}\beta_{c} \\
\mathrm{mV} / \mathrm{dec}\end{array}$ & $\begin{array}{l}R_{L P R} \\
\quad . \mathrm{cm}^{2}\end{array}$ & $\begin{array}{l}i_{\text {cor }} \\
\mu \mathrm{A} / \mathrm{cm}^{2}\end{array}$ & $\begin{array}{l}R_{s} \\
\quad . \mathrm{cm}^{2}\end{array}$ & $\begin{array}{l}R_{c t} \\
\quad . \mathrm{cm}^{2}\end{array}$ & $\begin{array}{l}R_{L} \\
\quad . \mathrm{cm}^{2}\end{array}$ & $\begin{array}{l}L \\
\mathrm{H} . \mathrm{cm}^{2}\end{array}$ & $\begin{array}{l}Q_{d l} \\
\mu \mathrm{F} / \mathrm{cm}^{2}\end{array}$ & $n$ \\
\hline (A) & -647 & 126 & 259 & 21.72 & 1,64 & 2.974 & 21.46 & 6.616 & 12.78 & 375 & 0.90 \\
\hline (B) & -636 & 207 & 273 & 8.56 & 8.29 & 2.986 & 3.71 & 1.182 & 0.24 & 638 & 0.89 \\
\hline
\end{tabular}

by a parallel inductance $(\mathrm{L})$ and resistance $\left(\mathrm{R}_{\mathrm{L}}\right)$. Some authors assigned it to the relaxation of the intermediates belonging to the adsorption phenomenon leading to a secondary passivity in the transpassive peak region $[31,32]$.We suppose that a part of $\mathrm{Cu}^{2+}$ ion is re-deposed by reduction reaction. According to G.Song [33], the state is an active adsorption. From these EIS results, it can be seen that the morphology of cementite has a significant effect on the impedance of the samples. This means that the passive layer is less stable for alloy (B); the values of $R_{c t}$ (charge transfer resistance) and $C_{d l}$ (double ionic layer capacity) deduced from spectrum impedance, showed a small values of $R_{c t}$ for alloy (B) however a sharp increase of the $R_{c t}$ with alloy (A) is observed, indeed, and inverse tendency was noted for capacity measurement. This increase in the capacitance $\mathrm{C}_{\mathrm{dl}}$ could be related to the growing area of copper deposit on the surface of the sample. In our particular case, the higher Lewis acidity $\mathrm{Fe}_{3} \mathrm{C}$ compared to metallic iron $(\alpha-\mathrm{Fe})$ sites present in the sample (B) provides a preferential site on the surface for the interaction with copper. This leads to microgalvanic cells between copper and ferrite phase ( $\alpha-\mathrm{Fe})$; resulting in selective dissolution of ferrite and in an influence on the kinetics by galvanic effect $[34,35]$.

On the basis of all the results obtained in this study, we propose the following schematic for the chosen alloys in sulfuric medium. With Fe-xC-5Cu|0.5 $\mathrm{M} \mathrm{H}_{2} \mathrm{SO}_{4}$ system containing dissolved oxygen, both ferrite phase and $\mathrm{Cu}$ dissolve, however the dissolved $\mathrm{Cu}$ re-deposits as $\mathrm{Cu}$ oxides [36]. This re-deposits is more pronounced in the case of $\mathrm{Fe}-1.5 \mathrm{C}-5 \mathrm{Cu}$, due to the attendance of $\varepsilon-\mathrm{Cu}$ phase. During the potentiodynamic polarization test, the process of $\mathrm{Cu}$ redeposition is more accelerated in $\mathrm{Fe}-1.5 \mathrm{C}-5 \mathrm{Cu}$ than in $\mathrm{Fe}-0.2 \mathrm{C}-5 \mathrm{Cu}$ alloy, by the cathodic polarization (high cathodic current Fig-5). As has been shown above, from Flade potentials, the local $\mathrm{pH}$ diminishes, and the cathodic overpotential in the hydrogen evolution is increased through $\mathrm{Cu}$ contribution [37]. The process involves into the following steps; dissolved oxygen 
and hydrogen cations coexist in the sulfuric acid solution. At the vicinity of the metal/solution interface, the composition of the Fe-xC-5Cu steels mainly consists of $\mathrm{Fe}$ with a small amount of Copper. When the Fe dissolves, the $\mathrm{Cu}$ may subsequently become detached from the metal surface. As the $\mathrm{Fe}-1.5 \mathrm{C}-5 \mathrm{Cu}$ steel does not have a uniform $\mathrm{Cu}$ network a preferential dissolution occurs of Fe adjacent the pro-eutectoid cementite. As soon as the $\mathrm{Cu}$ is separated from the surrounding carbide, the copper is oxidized to $\mathrm{Cu}^{2+}$ ions by reduction of the dissolved oxygen. When $\mathrm{Cu}$ is associated with ferrite phase, the Fe will be preferentially dissolved by galvanic corrosion; $\mathrm{Cu}^{2+}$ in a $\mathrm{Fe}, \mathrm{H}_{2} \mathrm{O}$ and $\mathrm{O}_{2}$ system acts as an oxidant to the ferrite phase. Therefore, a proportion of the $\mathrm{Cu}^{2+}$ will reduce and then re-deposit onto the substrate through a reduction reaction (consumption of the electrons produced by oxidation of the ferrite phase). The amount of deposit $\mathrm{Cu}$ should increase with an increase of the $\mathrm{Cu}^{2+}$ ion concentration in the solution [38].

With the Fe-0.2C-1.5Cu alloy, the selective dissolution and re-deposition process will repeat until the $\mathrm{Cu}$ enriched layer is stabilized. As a consequence of the $\mathrm{Cu}$ accumulation on the $\mathrm{Cu}$ containing steel surface, the resistance corrosion increase with an increase of the deposit copper. On the other hand, the phase angle maxima for $\mathrm{Fe}-1.5 \mathrm{C}-1.5 \mathrm{Cu}$ alloy are far removed from $90^{\circ}$, compared to $\mathrm{Fe}-0.2 \mathrm{C}-5 \mathrm{Cu}$ alloy. This deviation is related to the presence of a defective passive barrier film and no continuous layer can be present [39], the dissolution/redeposition process is disturbed by the presence of pro-eutectoid cementite. Thus, we can conclude that the hypereutectoid steel is more susceptible to pitting corrosion than the hypoeutectoid steel.

\section{CONCLUSION}

The effect of $\mathrm{Cu}$ on the corrosion resistance of both hypoeutectoid and hypereutectoid microstructures, in sulfuric media, is investigated. Conclusions are as follows:

Action of copper in $\mathrm{Fe}-\mathrm{xC}-5 \mathrm{Cu}$ alloys occurs as dissolution/re-deposition process.

The oxidation reaction of iron (active region), in both alloys, is not affected by the cementite morphology.

Copper increases significantly the corrosion resistance of $\mathrm{Fe}-0.2 \mathrm{C}-5 \mathrm{Cu}$ steel in sulfuric media, the improved corrosion performance could be associated with two factors: The remaining metallic copper at the surface reduces the overpotential of the cathodic reaction, hydrogen evolution. Copper dissolution makes the acid medium more oxidant; increasing the stability of the passive layer. 
The presence of dispersed $\varepsilon-\mathrm{Cu}$ and its interconnection with the pro-eutectoid cementite phase increases the susceptibility to localized corrosion.

The dissolution/re-deposition process, in hypereutectoid structure, is disturbed by the presence of pro-eutectoid cementite.

\section{ACKNOWLEDGEMENT}

The authors would sincerely like to thank Dr Aboki Tiburce "Laboratoire de Métallurgie Structurale" ENSCP Paris, France for his help in the smelting of alloys.

\section{REFERENCES}

[1] Pardo, A., Merino, M. C., Carboneras, M., Viejo, F., Arrabal, R., \& Munoz, J. Corrosion science, 2006. 48(5), 1075-1092

[2] Amara, S-E., Belhadj, A., Kesri, R., and Hamar-Thibault, S., Z. Metallkd., 1999, 90(2), pp.116-23

[3] Khorsand, H., Ghaffari, M., \& Ganjeh, E. Materials \& Design, 2014, 55, 979-986.

[4] Ahmed, I. M., Nayl, A. A., \& Daoud, J. A. Journal of Saudi Chemical Society. 2012, doi:10.1016/j.jscs.2012.11.003

[5] Huttunen-Saarivirta, E., \& Tiainen, T. Materials chemistry and physics, 2004, 85(2), 383-395.

[6] Zarrouk, A., Hammouti, B., Al-Deyab, S. S., Salghi, R., Zarrok, H., Jama, C., \& Bentiss, F. Int. J. Electrochem. Sci, 2012, 7, 5997-6011.

[7] Barouni K., Kassale A., Albourine A., Jbara O., Hammouti B., Bazzi L. Journal of Materials and Environmental Science, 2014, 5 (2) 456-463

[8] Yamamoto, A., Ashiura, T., \& Kamisaka, E. Boshoku Gijutsu, ,1986, 35(8), 448-454.

[9] Kim, D. R., \& Park, C. J. Solid State Phenomena, 2007, 124, 1557-1560.

[10] Sung-Lee, I., Kim, J. S., Kim, S. T., Kim, J. H., \& Lee, Y. YCorrosion Science, 2013, 70, 93-103.

[11] Ota, H., Ishii, T., Samukawa, T., Ujiro, T., \& Yamashita, H. In Materials Science Forum, 2010, (Vol. 638, pp. 3435-3440).

[12] Osório, W. R., Freire, C. M., Caram, R., \& Garcia, AElectrochimica Acta, 2012, 77, 189-197.

[13] Shu, J., Bi, H., Li, X., \& Xu, Z. Corrosion Science, 2012,57,89-98. doi:10.1016/j.corsci.2011.12.030 
[14] Liang, W. J., Rometsch, P. A., Cao, L. F., \& Birbilis, NCorrosion Science, 2013, 76, 119-128.doi:10.1016/j.corsci.2013.06.035

[15] Sil'man, G. I., Kamynin, V. V., \& Tarasov, A. A. Metal science and heat treatment, 2003, 45(7-8), 254-258.

[16] Durand-Charre.M. La microstructure des aciers et des fentes Genèse et interprétation. 2003, SIRP Editeur, Paris pp 241

[17] Russell, C, K., Brown L.M. Acta Metallurgica, 1972, 20, 7, 969-974

[18] Fourlaris, G., Baker, A. J., \& Papadimitriou, G. D. Acta metallurgica et materialia, 1995, 43(7), 2589-2604. doi:10.1016/0956-7151(94)00474

[19] Heo, Y. U., Kim, Y. K., Kim, J. S., \& Kim, J. K. Acta Materialia, 2012, 61(2) 519528

[20] Hou, Q., He, Y., \& Gao, J. Surface and Coatings Technology, 2006, 201(6), 36853690.doi:10.1016/j.surfcoat.2006.08.147

[21] Banas, J., \& Mazurkiewicz, A. Materials Science and Engineering: A, 2000, 277(1), 183-191. Doi:10.1016/S0921-5093(99)00530-4

[22] Fourlaris, G., Baker, A. J., \& Papadimitriou, G. D. Acta metallurgica et materialia, 1995, 43(10), 3733-3742. doi:10.1016/0956-7151(95)90157-4)

[23] Kandavel, T. K., Chandramouli, R., Manoj, M., Manoj, B., \& Gupta, D. K. Materials \& Design, 2013, 50 728-736. doi:10.1016/j.matdes.2013.03.037

[24] Fillabi, M. G., Simchi, A., \& Kokabi, A. H. Materials \& Design, 2008, 29(2), 411417. doi:10.1016/j.matdes.2007.01.004

[25] Carvalho, P. A., Fonseca, I., Marques, M. T., Correia, J. B., Almeida, A., \& Vilar, R. Acta materialia, 2005, 53(4), 967-976. doi:10.1016/j.actamat.2004.10.042

[26] Sazou, D., \& Pagitsas, M. Electrochimica acta, 2006, 51(28), 6281-6296. doi:10.1016/j.electacta.2006.04.010

[27] Frankel, G.S., Pitting Corrosion, Corrosion: Fundamentals, Testing, and Protection, Vol 13A, ASM Handbook, ASM International, 2003, 236-241

[28] Rahim, O., Ben Chenna, A., Zaiz, T., Chaouch, K., Lanez, T., Rev. sci. fond. app., vol. $3 \mathrm{~N}^{\circ} .2,2011,85-98$

[29] Sun, J. B., Zhang, G. A., Liu, W., \& Lu, M. X. Corrosion Science, 2012, 57, 131-138. doi:10.1016/j.corsci.2011.12.025

[30] Zhang, G. A., \& Cheng, Y. F. Electrochimica Acta, 2011, 56, 1676-1685. doi:10.1016/j.electacta.2010.10.059 
[31] Pushpanjali, M., Suma, A, R., Padmalatha, R., Journal of Materials and Environmental Science, 2014, 5 (2) (2014) 591-598

[32] Umoren, S. A., Li, Y., \& Wang, F. H. Journal of Materials and Environmental Science, 2010, 1(3), 189-196.

[33] Song, G., Bowles, A. L., \& StJohn, D. H. Materials Science and Engineering: A, 2004, 366(1), 74-86.

[34] Epelboin, I., \& Keddam, M. Electrochimica Acta, 1972, 17(2), 177-186.

[35] Feller H.G., Ratzer-Scheibe H. J., Wendt W. Electrochimica Acta, 1972, 17, 187-195

[36] El-Egamy, S. S. Corrosion Science, 2008, 50(4), 928-937.

[37] Kato, C., Grabke, H. J., Egert, B., \& Panzner, G. Corrosion science, 1984 24(7), 591611.

[38] Hermas, A. A., Ogura, K., \& Adachi, T. Electrochimica acta, (1995). 40(7), 8, $37-$ 844.

[39] Moretti, G., Guidi, F., \& Grion, G. Corrosion science, 2004, 46(2), 387-403.

\section{How to cite this article:}

Ferhat M. Benchettara A. Amara S E. Effect of copper on passivity and corrosion Behavior of fe-xc-5cu alloy. J Fundam Appl Sci. 2014, 6(1), 92-105. 